\title{
Opportunities and Challenges in Open, Distance and E Learning Education through the Lens of the Capability Approach Theory
}

\author{
Thulani Zengele \\ Department of Educational Management and Leadership, College of Education, \\ University of South Africa, South Africa \\ Email: tzengele@unisa.ac.za
}

\section{Doi:10.5901/mjss.2014.v5n23p1269}

\begin{abstract}
This conceptual article seeks to explore the capabilities, opportunities and challenges in Open Distance and electronic Learning Institutions through the Capability Approach Theoretical perspective. It views the learners' aspirations as the current determining factor by Academic Practitioners when modules and programmes are selected. I therefore argue that if the capability of learners, not what they aspire to enrol for is taken into account during the registration and orientation phase, throughput rates will be enhanced while dropout rates will be reduced in ODeL institutions. This stands to enable the achievement of the goals of the National Development Plan 2030 for Higher Education Institutions.
\end{abstract}

Keywords: Capability Approach Theory; ODeL; White Paper in Higher Education; National Development Plan 2030.

\section{Introduction}

This article examines the future, opportunities and challenges in Open Distance and electronic Learning (ODeL) education in the South African Higher Education sector. It also seeks the role ODeL aspires to play in personal, community, and national development. Although particular emphasis is in the South African context, discussions in this article may be regarded as reflective distance education experiences elsewhere in Africa and the world. President Nelson Mandela once said, education is the most powerful weapon which you can use to change the world http://www. forbes.com. Clearly, education is the key to human development and progress which makes it essential to bring about changes in attitudes, values, and behaviour. Used ethically, ODeL may enable people to undertake informed decisions about their present life and future if the country is to move ahead with the times. Moreover, these assertions have been credited to many scholars and institutions at one time or another like the Vice Chancellor and Principal of the University of South Africa Professor Mandla Makhanya during his various presentations that I will refer to later in this article. The question however is, to what extent are these assertions true? This question and more insightful issues constitute the substance of this article.

From the perspective of the Capability Approach Theory (CAT) by Dreze and Sen (2011) which emphasizes on the developmental approach towards education programmes attention is paid to the historical experiences of distance education in South Africa. The relationship between open and distance education institutions and the world of work is also discussed. The question of how ODeL could be geared towards the attainment of employment opportunities for learners that have opted to study through distance learning and electronic mode of learning is tackled in this article.

\section{Conceptual Framework}

The United Nations Development Programme, 2003 (www.undp.org/content/undp) describes development as a process that goes beyond the improvement of quality of life. It encompasses better education, higher health and nutrition standards, poverty reduction, a cleaner environment. It also increases access to and equivalence of opportunity, better individual freedom, and the facilitation of a more affluent cultural life. These are all said to be truthfully necessary culminations in themselves. By breaking the cycles of dispossession and hopelessness that are the first obstacles to every kind of development the UNDP's aim in developing countries is to eradicate extreme poverty and hunger and this is one of the objectives at the Department of Higher Education when drawing the policies on the White Paper in Higher Education (www.che.ac.za/.../education-white-paper) in South Africa. Schultz (1961) stated that education not only improves individual choices available to mankind, but an educated population provides an existence of skilled labour 
necessary for industrial development and economic growth. Dreze and Sen (2011) state that the intrinsic human value of education, which includes the capacity of education to add meaning and value to ordinary human lives without discrimination, make it a key component fundamental to universal human rights in South Africa.

In sum, education is the key that unlocks and protects the full spectrum of human rights. When deliberating on development from CAT, I articulate that development ensues when people are more able to attain what makes their lives beneficial to them. In my view people will be able to attain their goal when the circumstances at the institutions of higher learning establish an environment that is conducive to their success. What people value will vary from one individual to another and may include such ideals as those embedded in Maslow's hierarchy of needs which are crowned by the need for self-actualization. CAT shifts the goal of development from mere income as an end in itself, to that of growth of people and enhancing the quality of the desired human state. Viewing development from this perspective implies that it can be seen as a way of expanding the real freedom that people are striving for through education. The difference between a functioning and a capability is similar to the difference between an achievement and the freedom to achieve something, or between an outcome and an opportunity. Education, in this larger sense of term therefore becomes an instrument people can use to attain the level of freedom that they feel is intrinsically cherished. This also goes for achieving rudimentary levels of knowledge attainment like literacy and numeracy which serve as a functional key to grander educational development. Education and development policies based on CAT are considered to be successful if they enhance people's individual capabilities, whether or not they directly affect their economic growth and development.

\section{What is the Capability Approach Theory (CAT)?}

The Capability Approach Theory (CAT) is a comprehensive normative framework for the evaluation and assessment of individual well-being and social preparations, the design of policies, and proposals about social change in society. CAT is normally used in development studies. Sen (2007) contends that our evaluations, assessments and policies should concentrate on what people's capabilities are, who they really are or their lifestyle, and on removing obstacles in their lives so that they have more freedom to live the kind of life that they, upon reflection, have reason to value. This can be achieved when reviewing or eradicating those policies and practices that are regarded as a hindrance to meaningful development and replacing them with policies that are geared towards the development of learners in ODeL institutions.

The distinction between achieved functioning and capability is between the achieved and the effectively conceivable; in other words between achievements on the one hand and freedom or valuable options from which one can choose on the other. What is ultimately important is that people have freedom and opportunities to lead the kind of lives they want to lead, to do what they want to do and be the person they want to be in an ODeL environment. This is possible because in this environment learners have the opportunity to study while pursuing their careers. Once they effectively have these essential opportunities, they can cherry-pick those options that they value the most. For example, every person should have the opportunity to be part of a community and to practice a religion, but if someone prefers to be a hermit they should be free to select this option in the new South Africa without the possibility of any form of harassment.

It is important to highlight that CAT cannot explain poverty, inequality or well-being; instead it rather provides an instrument and a framework within which to conceptualize and evaluate these occurrences. Applying CAT to issues of policy and social change will therefore often require the addition of explanatory theories that are not part of this article discourse. The core characteristic of CAT is its focus on what people are effectively able to do and to be; that is, on their capabilities. This ought to be the focus of the department of Recognition of Prior Learning at the Institutions of Higher Learning when considering new applications for admission and assisting students to make meaningful choices regarding their modules, diplomas and degrees. This contrasts with the philosophical approaches that concentrate on people's happiness, income, expenditure, or consumption. The approach in its present form has been pioneered by the economist and philosopher Amartya Sen and has more recently been significantly developed by the philosopher Martha Nus.

According to CAT, the ends of well-being, justice and development should be conceptualized in terms of people's capabilities to function; that is, their effective opportunities to undertake the actions and activities that they want to engage in, and are who they want to be. These beings and doings, which Sen (2007) calls functioning together constitute what make a life valuable and meaningful. According to Sen (2007) functioning includes working, resting, being literate, being healthy, being part of a community, being respected, and so forth. The distinction between achieved functioning and capabilities is between the realized and the effectively possible; in other words between achievements on the one hand and freedoms or valuable options from which one can choose on the other.

CAT evaluates policies according to their impact on people's capabilities. It poses a question whether people are ready to be incorporated into the Open and Distance Learning mode, and whether the means or resources necessary for this capability are present. It enquires whether people are well prepared and ready to engage with their learning 
programmes, and whether the conditions for this capability, such as having bursaries and other forms of financial assistance, are being met. CAT probes whether people have access to a high-quality educational system, to real political participation through their Learner Representative Councils. Community activities that support them to cope with struggles in daily life which foster real associations are also checked. For some of these capabilities, the main input will be financial resources that are available and accessible and economic production once the qualification has been completed. Anything worthy has certain characteristics, which make it of interest to people. For example, people are not necessarily interested in a car because it is an object made from fibre glass with a specific shape, colour and prestige, but because it can take one to places where they want to go to, and in a faster and comfortable way that is much more convenient compared to walking. Let us consider an example of the choice of the qualification one chooses to register for, at an institution of higher learning.

Is it the case of a choice between a degree and a diploma that matters or is it whether it will be a degree or diploma that will provide one with a career that one has always wanted to follow after qualifying that matters? The characteristic of a good qualification that is obtained from a reputable institution of higher learning enables the functioning and use of the qualification. In my example, the car enables the functioning of motion to be able to move oneself independently and more speedily than walking. A person that completes a Junior Certificate qualification and enrols at a local technical college with the goal to obtain a qualification in fixing electrical appliances because following their dream of becoming an electrical engineer one day would have taken years to realize the goal of self-actualisation could be the case in point. The best route at the time for the learner would have been to pursue the college certificate instead of enrolling at an institution of higher learning to do a degree in Electrical Engineering. This depended on the work of the academic and career advisor at university.

Crocker (as cited by Sen, 2010) posit that the relation between a good and the functioning to achieve certain beings and doings is influenced by three groups of conversion factors. First, personal conversion factors like physical condition, sex, reading skills and intelligence may influence how a person can convert the characteristics of the commodity into a functioning. If a person is disabled, or in a bad physical condition, or has never learned to drive a car, then the car will be of limited help to enable the functioning of movement. It is therefore important that ODeL institutions develop effective means of ensuring that learners that are admitted to suitable programmes have the ability to effectively utilise them after graduating. Secondly, social conversion factors like public policies, social norms, discriminating practises, gender roles, societal hierarchies and power relations will ensure that the factors that limit the upward mobility of learners are removed from the system or restructured. Thirdly, environmental conversion factors like climate and geographical location could play a role in the conversion from characteristics of the good to the individual functioning. This becomes possible in the sense that the geographical location of the institution sometimes determines the qualifications that will benefit the learners. An example could be in institutions of higher learning situated in the mining community and offering courses in geology which are relevant to societal economy.

At this point an alternative view to the issues raised above could be that if a government or the dominant societal culture imposes a social or legal norm that women are not allowed to go to school, then it becomes much more difficult to use the good to enable the functioning. Hence, knowing the good a person owns or can use is not sufficient to know which functioning he or she can achieve. ODeL institutions need to know much more about their registered learners by bringing the university to the people and not the other way round as the University of South Africa is doing although this is not always possible because of the distance between learners and the institution and among learners themselves. This is the reason ODeL institutions have to find ways of removing the distance out of distance education itself by engaging in electronic systems of tuition and learning. This could be done by entrenching tuition and learning material that interacts and engages the learner rather than instructing the learner. CAT not only advocates an evaluation of people's capability sets, but insists also that we need to scrutinize the context in which economic production and social interactions take place, and whether the circumstances in which people choose from their opportunity sets are enabling and just. In this case the existence of ODeL institutions needs to be examined and assisted if it serves this important function.

In precipitation, all the means of well-being, like the availability of commodities, social institutions and so forth are important, however CAT emphasizes that they are not the ultimate ends of well-being. A second terminological note concerns the meaning of the term 'basic capabilities'. In Sen's work (2011), basic capabilities are a subset of all capabilities; they refer to the freedom to do some basic things that are necessary for survival and to avoid or escape poverty by all means. These basic capabilities may not include acts of criminality like the abuse of religion, white collar or common crime. The saying, if crime does not pay try religion and if religion does not pay as well...try politics could have been attributed to the notion I have just referred to. The relevance of basic capabilities is "not so much in ranking living standards, but in deciding on a cut-off point for the purpose of assessing poverty and deprivation" which is what should determine how long we spend in our studies or the qualification we have opted to pursue in higher learning. While the 
notion of capabilities refers to a very broad range, basic capabilities refer to the real opportunity to avoid poverty and not just a question of failing to differentiate between needs and wants in our daily lives.

It is also important to acknowledge that CAT is not restricted to poverty and deprivation analysis, or development studies, but can also serve as a framework for project or policy evaluations of inequality measurement in affluent communities. In addition to these two terminological remarks, a few things need to be said about the use of functioning versus capabilities in assessment practices and policy formulation. First, it should be noted that there are situations where it makes more sense to investigate people's achieved functioning directly, instead of evaluating their capabilities. This implies that what has been achieved is more valuable than what we are capable of doing for the latter can only be an unachieved or the not yet achieved dream.

For example, if we are focusing on the capability of bodily integrity, we will not be concerned about a wrestler who deliberately puts him or herself in danger of being punched and thrown to the canvas. He has the capability of not sustaining injury, but chooses to wrestle. But as far as sexual harassment is concerned, we can use the very plausible assumption that no-one wants to be sexually harassed by another person in the same workplace. If a person's achieved functioning of bodily integrity is harmed by sexual harassment, then this is an indisputable sign that the casualty did not have the know-how of being innocuous from corporal harm at the outset. This is important for assessing which policies can reduce gender inequalities, because intervening in the distribution of resources will be a fundamental technique of affecting the distribution of capability well-being.

This can be attributed to individuals that enter the ODeL arena without passable intellectual and scholarly integrity to handle open distance learning programmes that are offered without the potential of physical harm to their intellectual and brain functioning. This goes on until they graduate with their lucidity intact. On the other hand, if people fail to realise their capability when opting for learning programmes in ODeL institutions and engage in careers that are not suited to their capabilities, they risk the danger that the little they have left in their capacity to think rationally when they could have opted for more practical easier to tackle options instead. The learner support and career advisors at ODeL institutions have the responsibility to ascertain this does not occur so that learners reach their goal of self-actualisation. The third strength of CAT is that it explicitly acknowledges human diversity, such as race, age, ethnicity, gender, sexuality, and geographical location as well as whether people are handicapped, pregnant, or have other limitations.

\section{The Face of ODeL Today}

According to the White Paper on higher education projects in 2011 (www.che.ac.za/.../education-white-paper) there were just over 937000 students in ODeL institutions and this number could increase to about 1.6 million enrolments by 2030. This implies that in order to prepare for this influx, institutions of higher learning must simultaneously focus their attention on improving learner performance, student access, success and throughput rates which must become a national priority. Gender equity and disability issues including the development of the scarce and critical skills are highly essential for South Africa's economic development which calls for the application of CAT principles when tackling these challenges. Other commitments made in the White Paper (ibid) include:

- The progressive introduction of free education for the poor in South African universities as resources become available;

- A new Central Applications Service (CAS)

- Increasing research and innovation, improving the quality of research, and building on areas of strength identified as important for national development.

- The development of a policy for the staffing of universities and the retention and growth of academia.

- The establishment of A National Institute for Humanities and Social Sciences and

- Support for the study of African languages.

Strong partnerships and collaborations are encouraged across all sectors, especially with the newly named Technical Vocational Education and Training (TVET) colleges (former FET colleges). Universities are encouraged to establish strong partnerships with employers in order to promote the expansion of workplace training opportunities, especially in those areas where qualifications or professional registration depends on practical workplace experience. Given such conditions, ODeL stands to play an increasing role in such partnerships, both in terms of training TVET staff, its vocational offerings and the development of cooperative and industrious partnerships with employers because of the nature of their operations. Most importantly, ODeL institutions allow learners to function as interns while studying because of the distance and electronic mode of learning. Key to this relationship of course will be paths of articulation in and between the institutions, their courses and qualifications. This will require a more collaborative and premeditated approach to courseware development and a quality regime of well suited course designers. The University of South Africa 
(Unisa) has a very well established Department of Curriculum and Learning Development (DCLD) unit that specialises in interactive courseware design using specific software.

In terms of the National Development Plan 2030 on (www.gov.za/issues/national-development-plan), South Africa needs to produce 30000 artisans a year to help grow the economy of the country and reduce poverty. At present the country is training an average of 12000 qualified artisans a year. The government is determined to meet the target set in the NDP and is collaborating with the various partners across the public and private sector to make it happen. This is what Unisa is engaged in to ensure learners and programmes are geared to towards the development of the economy.

During the speech that the Unisa Vice Chancellor and Principal Professor Makhanya on (www.unisa.ac.za/alumninews/wp ) made in the Eastern Cape in 2011, he stated that the country desperately needed new knowledge of dedicated and focussed research, human capital consisting of skilled and employable citizens. He continued to say (ibid) that institutions of higher learning have a fundamental role to play in all of these. He emphasized that for the survival of ODeL institutions there should be the departure from the position when higher education institutions could operate as ivory towers, selecting research topics that have little or no relevance or application to broader society (ibid). Research should be turned around and move away from trivial petty issues and to projects that will be beneficial to communities which involves all stakeholders. It is the graduates in ODeL institutions that have to be trusted with making the correct choice when selecting topics and programme areas for research that will benefit them when seeking employment. The job hunting element could be turned around to become the employers hunting for ODeL graduates because of their rich background that is coupled with direct relevance to the real world of work to escape poverty.

Graduates in ODeL institutions are the human capital that will not only be employable, but that they will have a range of competencies and qualities that will enable them to become job creators in their own right and not mere employees. It means using the qualifications and skills that are acquired not only to further their own careers but also to make a deliberate and purposeful contribution to the common good and the socio-economic development of communities and the country. Development further suggests that can conduct themselves in an ethical manner, and with such integrity that others from their own families will feel inspired and motivated to emulate the example of ODeL graduates. Success means investing wealth in their name and a sound reputation that is more than in monetary terms but dealing with the ugly prospect of poverty. When this is acquired a legacy that others will be gratified to follow will be created. One of the most attractive things about being in an ODeL environment is that one is able to study at any age, under any circumstances and one needs to bear that in mind as one embarks on a journey of knowledge acquisition.

\section{Challenges in ODeL}

Makhanya (2013) paints a bleak picture of South African Higher Education, echoing many of the global trend sand dynamics. Key amongst these are:

- The ongoing global recession that has exacerbated our national socio-economic and political woes;

- The potential and pitfalls of technological innovation;

- The growing phenomenon of internationalisation with the attendant commercialisation of education;

- Crises of leadership and management relentless calls for (free) access against a backdrop of widespread poverty;

- Concerns about the quality and relevance of our qualifications; unsatisfactory levels of student support;

- The changing nature of the academic and the academe;

- The calibre and preparedness for work or professions of the graduates that we produce; and

- Serious deficits in terms of access to the internet in South Africa. The last challenge is already getting attention with the beginning of the roll out of the internet starting with the Tshwane metro in 2014.

While one of Makhanya's major concerns is the likely loss of students to traditional universities, my view is that due to the rising costs of higher education in South Africa Unisa still continues to attract more learners because of the lower fees. The second major reason for Unisa's projected growth is Unisa's 140 years in the ODL sector with the capacity to design interactive learning material that enables learners to study while pursuing their careers. The other concern is that good academics may leave has been swept away by the recent upgrading of salary packages of all academics making Unisa one of the highest paying institutions of higher learning.

According to Makhanya this is true for both basic and higher education, and there has been a serious decline in both the quality of education and the calibre of students who eventually find their way into institutions of higher learning. This is particularly noticeable when it comes to ODeL learners who often come from more underprivileged backgrounds than those students who meet admission criteria for contact institutions because of the presumed less tuition expenses. 
This poses serious challenges in terms of student counselling and support and in assisting students into the desired levels of competency, proficiency and appropriate study habits.

The Green Paper for Post School Education and Training (2012) (www.che.ac.za/.../dhet-green-paper) indicates that despite the many advances and gains made in South Africa since 1994, the education system continues to produce and reproduce gender, class, racial and other inequalities with regard to access to educational opportunities and success. One of the greatest challenges facing the system is the concern raised by various analysts concerning a large number of young people who face a very bleak future if major changes are not introduced. A major problem in the system as a whole is that the provision of post-school education and training is inadequate in quantity, diversity and, in many but not all instances, quality. This is the case since most of the crucial policies have to be re aligned to remove barriers that deny access to Black learners who form the majority in student enrolments in Higher Education. Approximately five million young learners between the ages of 18 and 24 are not accommodated in either the education and training system or the labour market according to the White Paper in Higher Education (2013) (www.che.ac.za/media.../white-paper). This is an appalling waste of human potential, and a potential source of serious social instability which CAT seeks to alleviate when applied.

\section{Opportunities for ODeL}

On 3 February 2014 the Minister of Higher Education is South Africa, Blade Nzimande launched a ten-year campaign called 2014 - 2024 Decade of the Artisan (www.sabceducation.co.za/index.php), which will be run under the theme: "It's cool to be a 21st Century Artisan". The Decade of the Artisan campaign seeks to promote artisanship as a career of choice to South Africa's youth within the post school education and training system as well as to highlight skills development opportunities that are available for artisans. In terms of the National Development Plan (NDP) (www.gov.za/issues/national-development-plan), South Africa needs to produce 30000 artisans a year to help grow the economy and reduce poverty. At present the country is training an average of 12000 qualified artisans a year. The government is determined to meet the target set in the NDP and is collaborating with various partners across the public and private sector to achieve this goal. This stands to provide a clear sense of the determination and drive that is marking the development of this sector.

According to the White paper (ibid) the DHET will investigate the possibility of providing distant education programmes at the TVET and community college levels including dedicated staff and equipment. The theoretical apprenticeships including the leadership programmes might also be offered through distance education especially for those students who live or work far from an appropriate college or those who prefer this model. In this instance, Unisa's slogan of 'taking the university to the people' and not the other way round' is followed.

The return of educationists from exile and the mass movement of intellectuals of African descent to developed countries during the apartheid era and immediately before and after the first democratic elections are now turning into a consecration. Education experts, many of whom have returned home, have started ploughing back their skills and knowledge gained abroad into the development of their communities. As such, South Africa is now beginning to witness the reversal of the brain drain.' The cross fertilization created by this influx however, must be sustained through incentives and improved infrastructure designed to prevent frustration and regret of those intellectuals and highly trained individuals returning home.

\section{Africa Development}

Human resource development and leadership have equally benefited from the first distance university in Africa. The University of South Africa (UNISA) which was established in 1873 has contributed to the emergence and accreditation of many distance education institutions throughout South Africa. This has assisted in developing the capacity of distance education experts across the continent. In addition, the integration of HIVI AIDS preventive education into the mainstream programmes is one of the flagship initiatives by Unisa. Distance education has helped to reduce discrimination and stigmatisation faced by those living with HIVI AIDS. As a result, Unisa has an established HIV office that is manned by a manager with support staff and aims to ensure that those who are infected or affected are able to work in an environment that is free of harassment. This programme strives to achieve this goal through the broadcast of public education programmes via Unisa radio, national television, community industrial theatres, posters and schools. Such broad-brush programmes have empowered illiterate individuals as well as those who have gone far with schooling like those who have engaged in such distance learning systems to acquire information and knowledge on how HIVIAIDS is transmitted and how it can be avoided. 


\section{Conclusion}

In conclusion, I am not yet convinced that the future shape of South African Open Distance and electronic Learning Institutions will mirror the shape of education in developed countries for example, to the extent that it does at the moment because of restrictive policies on the admission of learners and payment of fees. Neither am I convinced that the South African ODeL will mirror that which one might find in developed countries in the future. I have reason to suspect that as the world hiatuses and ODeL education engages in higher gear we might find some very different Higher Education models emerging, including the Unisa copycats that I have repeatedly referred to in this article as a possible cause for concern. There should be pluck and confidence as challenges are tackled to maximise prospects and minimize challenges that shape the unique ODeL identity during the $21^{\text {st }}$ century.

\section{References}

Amartya, A. 1973. The Capability Approach: a theoretical survey. Journal of Human Development: http://www.tandfonline.com/loi/cjhd19. [date accessed 2014/03/16].

Crocker, D.A. 2008. Ethics of Global Development. Agency, Capability and Deliberate Democracy. Cambridge University Press: New York, USA.

Department of higher Education and Training. 2014 The Green Paper for Post School Education and Training. Also at www.dhet.gov.za [date accessed 2014/03/16].

Department of higher Education and Training.2013. White Paper Published for Post School Education and Training. Also at www.dhet.gov.za [date accessed 2014/03/16].

Dre`ze, J. and Sen, A., 2002. India: Development and Participation, Oxford University Press: Oxford.

Makhanya, M. (2014). Discussion of the launch of the new White Paper of Higher Education Pretoria: UNISA. http://www.tonybates.ca /2014/03/16/new-policies-for-online-learning-and-distance-education-in-south-africa/\#sthash.0tOUOsSK.dpuf [date accessed 2014 103/16].

Makhanya, M.S. 2011. Keynote address: Port Elizabeth alumni breakfast. 25th JUNE 2011.

Makhanya, M.S. 2013. Advancing Gender Equality in Higher Education and the Broader Society.

Speech presented at the ZK Matthews Great Hall, Muckleneuk campus: 2 August 2013.

Makhanya, M.S. 2013. Welcome address: commonwealth conference on the education and training of youth workers (ccetyw 2013). Speech presented at the ZK Matthews Great Hall, Muckleneuk campus: 19th March 2013.

Nussbaum, M. 1988. "Nature, Function and Capability: Aristotle on Political Distribution." Oxford Studies in Ancient Philosophy. Supplement:145-184.Oxford, UK: Oxford University Press.

Republic of South Africa. 2013. White paper for Post-School Education and Training Pretoria SA: Department of Higher Education and Training. [date accessed 2014/03/16]. http://www.tonybates.ca/2014/03/16/new-policies-for-online-learning-and-distanceeducation-in-south-africa/\#sthash.0t0U0sSK.dpuf

Republic of South Africa. 2013. White paper for Post-School Education and Training Pretoria SA: Department of Higher Education and Training - See more at: www.che.ac.za/.../education-white-paper [date accessed 2014/03/16].

Robeyns, I. 2003. 2011. Sen's Capability Approach and Gender Inequality: selecting relevant Capabilities. Feminist Economics. 9, 6192. http://www. tandfonline.com/loi/rfec20: [date accessed 2014/03/16].

Sen, A. 2010. Contemporary Philosophy in Focus. Cambridge University Press: New York, USA.

Schultz, T.W. 1961. "Education and Economic Goals". The American Economic Review. 51: 1-19.

\section{Electronic Sources}

19 Inspirational Quotes from Nelson Mandela. 2013. http://www.forbes.com/sites/mfonobongnsehe/2013/12/06/20-inspirational-quotesfrom-nelson-mandela

http://www.forbes.com

www.undp.org/content/undp

www.che.ac.za/.../education-white-paper

www.sabceducation.co.za/index.php

www.gov.za/issues/national-development-plan

www.che.ac.za/.../dhet-green-paper 